\title{
A PREVALÊNCIA DE IMAGINÁRIOS ESTEREOTIPADOS DO BRASIL NO EXTERIOR E O PAPEL DAS MÍDIAS NA SUA MANUTENÇÃO
}

\author{
Maria Badet ${ }^{1}$
}

\begin{abstract}
O artigo versa sobre a relevância que têm os meios de comunicação para a construção da imagem e imaginários do Brasil no exterior. Para entender este universo, são apresentados resultados dos trabalhos de Badet (2015), compostos pela análise de mais de 160 notícias sobre o Brasil na mídia espanhola. O estudo também analiza como os conteúdos podem ser interpretados com base no trabalho de campo de dois anos realizado junto a 121 jovens espanhóis. Tanto ao analisar os conteúdos, como os processos de apropriação, comprova-se a importância mídiatica e social da mulher brasileira como representante do imaginário social do Brasil, sendo este muitas vezes associado ao erótico e sensual. Os resultados nos levam a pensar sobre o papel primordial das mídias para a construção de imaginários do Brasil menos esteriotipados.
\end{abstract}

Palavras-chave: imaginário social do Brasil, apropriação conteúdos mídiáticos.

\section{Introdução}

A imagem e os imaginários de um indivíduo, coletivo, cultura e/ou país são processos sociais complexos que podem ser analisados desde diferentes âmbitos acadêmicos. Neste amplo universo de análise, é crescente o número de estudos que consideram o papel dos meios de comunicação e as interações midiáticas para o compartilhamento e difusão de imaginários de um sujeito em relação à identidade de um "outro", tal como expõe Nash². A importância midiática é ainda reforçada pelo fato de vivermos em um mundo globalizado marcado pelo amplo acesso a informação e convergência de mídias. Precisamente por

1 Pontifícia Universidade de Minas Gerais. Belo Horizonte, MG, Brasil.

$2 \mathrm{NASH}$, Mary. Representaciones culturales, imaginarios y comunidad imaginada en la interpretación del universo intercultural. 
isso os meios de comunicação são de suma importância cidadã para conectar as diferentes culturas e sociedades e, assim, contribuem de maneira cada vez mais significativa no complexo processo de construção dos imaginários sociais.

Neste artigo, nos centramos em explicar a relevância dos meios de comunicação para a construção da imagem e imaginários do Brasil, brasileiros e brasileiras no exterior. Para isso, utilizamos como base alguns dos principais estudos acadêmicos feitos sobre meios de comunicação e imaginários que vigoram do Brasil, principalmente na Espanha, Portugal e Estados Unidos nas duas últimas décadas ${ }^{3}$. Com base neste marco teórico amplo, apresentamos neste texto alguns resultados dos trabalhos de Badet ${ }^{4}$ centrados em estudos desenvolvidos nos últimos sete anos relacionados aos conteúdos midiáticos apresentados sobre o Brasil na mídia espanhola. Neste texto, destacaremos alguns dados de uma das mostras coletadas composta por mais de 140 notícias sobre o Brasil na Espanha e, posteriormente, alguns resultados do trabalho de campo feito junto a 121 jovens espanhóis no qual foram observadas as diferentes formas como esses conteúdos podem ser interpretados e apropriados. A partir destes materiais, a autora faz considerações sobre como estes conteúdos interferem na formação de valores e imaginários sobre o Brasil, brasileiros e brasileiras. Para completar os objetivos deste artigo, apresentamos alguns dados sobre a importância e impacto que as comunidades brasileiras residentes no exterior julgam ter os imaginários do Brasil nos países onde residem. Para tal, citamos alguns dados obtidos de um questionário aplicado junto a 46 representantes de associações e conselhos de cidadania/ cidadãos em 19 países $^{5}$. Como se poderá constatar no transcorrer da leitura, a importância midiática e social da mulher brasileira como representante do imaginário social do Brasil ganha destaque em todas estas etapas expostas no artigo, sendo este um relevante aspecto para as reflexões finais do trabalho.

Por fim, com base nesta ampla análise, esperamos oferecer aos leitores alguns esclarecimentos sobre o papel primordial das mídias na construção do imaginário social do Brasil, dos brasileiros e das brasileiras no exterior. Com isso, a intenção é despertar nos leitores o interesse e a necessidade de que sejam cada vez mais utilizados os espaços midiáticos como importante ferramenta

3 BADET, Maria. Periodismo e imaginarios: Brasil más allá de lo tropical y lo sensual; FERIN CUNHA, Isabel (coord.). A televisão das mulheres: ensaios sobre recepção; MACHADO, Igor J. Imigrantes brasileiros no Porto. Aproximação à perenidade de ordens raciais e coloniais portuguesas; PADILLA, Beatriz. Brasileras en Portugal: de la transformación de las diversas identidades a la exotización; RIBEIRO, Gustavo Lins. Tropicalismo e Europeísmo. Modos de representar o Brasil e a Argentina; SALES, Teresa, LOUREIRO, Márcia. Imigrantes brasileiros adolescentes e de segunda geração em Massachusetts, EUA.

4 BADET, op. cit.

5 O questionário mencionado foi aplicado via coordenação da Mesa de Temas Sociais do Conselho de Representantes Brasileiros no Mundo - CRBE, em julho de 2014. Trata-se de um questionário diagnóstico das problemáticas de gênero e sexualidade identificadas por líderes da sociedade civil em seus países de residência. 
para ampliar os imaginários do Brasil no estrangeiro e, assim, contribuir para o reconhecimento da diversidade social brasileira.

\section{O Brasil imaginado e o papel das mídias}

Nos anos 80, quando se intensificam os fluxos migratórios de brasileiros para o exterior, passam a ganhar visibilidade e relevância as imagens e os imaginários ${ }^{6}$ sobre o Brasil e os brasileiros em outros países. Diferentes estudos já demonstraram que estes imaginários estão longe de representar a pluralidade social e cultural do Brasil e, consequentemente, a diversidade de grupos que emigraram do país ${ }^{7}$.

Ribeiro $^{8}$ destaca que os imaginários do Brasil se constroem a partir de uma visão tropicalista que remonta à época da chegada dos portugueses ao país, como, por exemplo, a imagem exótica das índias nuas descrita por Pedro Álvares Cabral. Ao longo dos mais 515 anos desde a chegada dos portugueses, pouco se fez e avançou para mostrar internacionalmente o Brasil além do imaginário tropicalista, ainda que nos últimos anos estejam aumentando os esforços nesta direção pelo governo brasileiro, sociedade civil organizada residente no exterior, assim como por governos e meios de comunicação de alguns países de acolhida ${ }^{9}$. Infelizmente, mesmo com estes esforços, o que ainda prevalece são as imagens de um país alegre, de gente com corpos exuberantes, que tem como marca o carnaval e o futebol.

A promoção dessa imagem internacional do Brasil tem refletido de maneira indireta ou direta na vida dos brasileiros e das brasileiras que, por diferentes motivos, tomaram a decisão de emigrar do Brasil. No seu dia a dia, estes migrantes passam a conviver cotidianamente com pessoas que já dispõem de um repertório e percepções pré-estabelecidas sobre o Brasil e o que vem a ser um brasileiro ou brasileira. Sem dúvida, não é privilégio da comunidade brasileira que emigra conviver com visões reduzidas e/ou estereotipadas sobre o que vem a ser suas identidades ${ }^{10}$ associadas ao Brasil. Nos processos migratórios, essas

${ }_{6}$ A construção do sujeito é um processo complexo e continuo marcado pela interação com o mundo. Como pondera Mulvey (MULVEY, Laura. Placer visual y cine narrativo), a imagem leva ao o imaginário, reconhecimento e identificação a partir da articulação de um sujeito com o mundo. Entendemos as imagens como estruturas cognitivas ativas com capacidade de provocar diferentes reações e ativar imaginários, tal como Buxó (BUXÓ, María Jesús, MIGUEL, Jesús de (eds.). De la investigación audiovisual. Fotografía, cine, video, televisión).

7 GARCÍA, Loreley. La migración de brasileños en el contexto de la globalización; RIBEIRO, Gustavo Lins. Identidade Brasileira no Espelho Interétnico. Essencialismos e Hibridismos em San Francisco; SALES, LOUREIRO, op. cit.

8 RIBEIRO, Identidade Brasileira..., op. cit.

9 Nos meios de comunicação dos países com relevante presença de comunidade brasileira, ainda que tenda a prevalecer programas e notícias associadas ao imaginário tropicalista, também existem programas e notícias preocupados em mostrar de maneira contextualizada a diversidade da cultura e sociedade brasileira. Como exemplo, citamos os programas Volta Món de 13/08/2009 e o programa Españoles por El Mundo da TVE (BADET, op. cit.).

${ }^{10}$ Assim como Barker (BARKER, Chris. Televisión, globalización e identidades culturales), defendemos 
visões atravessam também as percepções dos próprios brasileiros em relação a outras nacionalidades. Defendemos que um maior conhecimento sobre as outras nacionalidades e culturas pode potencializar o deslocamento de visões de mundo reducionistas e estigmatizadas para visões mais plurais e contextualizadas das diversidades de perfis sociais que compõem uma nação e/ou cultura. Neste sentido, as mídias têm funcionado como instâncias de construção e mediação de imaginários, e, conforme sua atuação, podem colaborar para o reforço ou para o deslocamento dos estereótipos sobre o Brasil.

No âmbito das migrações, as mídias potencializam o conhecimento da diversidade social dos diferentes grupos que compõem, na atualidade, os movimentos migratórios. Como lembra Nash ${ }^{11}$, o consumo de mídias no mundo transnacional pode facilitar ou obstaculizar o reconhecimento e inserção dos imigrantes dentro de uma comunidade imaginada. Por exemplo, muitas sociedades de acolhida de imigrantes brasileiros em Portugal, Espanha e Estados Unidos têm uma imagem tropicalista do Brasil que colabora para a produção de marcas identitárias coletivas relacionadas aos imigrantes brasileiros que podem ser geradoras tanto de inclusão como de exclusão. Ou seja, por um lado, traços como a alegria brasileira podem ajudar a integrar e, por outro, a associação da mulher brasileira com a sensualidade pode ser um fator de exclusão. Em síntese, a comunidade imaginada do Brasil pode ser aceita ou negada, segundo as pessoas e os contextos de inserção.

Como já foi mencionado em diferentes estudos ${ }^{12}$ e também em levantamentos de órgãos governamentais ${ }^{13}$, um alto número de brasileiros e brasileiras são vítimas de problemas relacionados diretamente às temáticas de gênero e sexualidade nos países onde decidiram imigrar. Para observar a percepção social das comunidades sobre o tema, em 2015 foi aplicado um questionário junto a 46 líderes comunitários de diferentes países com importante presença de comunidades brasileiras no exterior ${ }^{14}$. Uma das perguntas indagava sobre quais

que o conceito de identidade não se refere a uma identidade universal, fixa e essencial, mas a construções sociais, culturais e históricas. Ou seja, não possuímos uma identidade e sim somos formados por uma complexa rede de atitudes e crenças. Portanto, optamos pelo uso do termo identidades no plural, considerando que a identidade varia segundo o contexto.

$11 \mathrm{NASH}$, Mary. Repensar las representaciones mediáticas de las mujeres inmigrantes.

12 BADET, op. cit.; PISCITELLI, Adriana. Trânsitos: brasileiras nos mercados transnacionais do sexo; SILVA, Marcos. Dinâmicas da Migração Brasileira e Crise do Welfare State na UE Pós-2008: Uma Etnografia a partir de Roma e Barcelona.

${ }^{13}$ MINISTÉRIO DA JUSTIÇA. Relatório Nacional sobre Tráfico de pessoas: consolidação dos dados de 2005 a 2011; OIT. Enfrentamento ao tráfico de pessoas no Brasil (2004-2011): avaliações e sugestões de aprimoramento de legislação e políticas públicas; UNODC. Global Report on Trafficking in Person 2012.

${ }^{14}$ Das 46 respostas, a maior parte (25 respostas - 54,3\%) procedera de países do continente europeu. Ainda relativo ao perfil dos participantes, é importante mencionar que, dos questionários aplicados, 31 foram respondidos por representantes dos Conselhos de Cidadão e Cidadania dos diferentes países e as outras 15 respostas foram de membros de outras instâncias de representatividade da sociedade civil organizada. Portanto, participantes que, em seu dia a dia, atuam junto à comunida brasileira. 
problemas de gênero e sexualidade vividos pela diáspora brasileira consideravam mais relevantes. Para fundamentar esta pergunta, foi elaborada uma tabela com treze temas que, a partir de análises realizadas em estudos anteriores, identificamos como presentes em maior ou menor grau em diferentes países. Os itens da tabela foram oferecidos como opção de resposta para a seguinte pergunta: Quais assuntos você identifica como problemas vividos pela comunidade brasileira na sua região? Com base na análise das respostas, constatamos que as mulheres e coletivos LGTBI são vistos como as principais vítimas dos problemas relacionados às questões de gênero e sexualidade na maioria dos 19 países participantes do estudo. Os principais problemas referidos, nesse âmbito, são as agressões e os preconceitos, seguidos pela violência doméstica e os problemas gerados por imagens estereotipadas das comunidades, conforme aparece sintetizado na tabela a seguir:

Tabela 1

\begin{tabular}{|c|cc|}
\hline \multicolumn{3}{|c|}{$\begin{array}{c}\text { Quais assuntos você identifica como problemas vividos } \\
\text { pela comunidade brasileira na sua região? }\end{array}$} \\
\hline Ranking & Temas & 39 \\
\hline 10 & Agressões e preconceitos & 37 \\
30 & Violência doméstica & 32 \\
40 & Imagem estereotipada que prejudica a convivência social & 29 \\
50 & Violação de direitos em casamentos com nacionais de outros países & $\mathbf{2 7}$ \\
\hline
\end{tabular}

Fonte: Questões de Gênero e sexualidade no exterior, 2015.

Pelos dados analisados constatamos que para 32 dos 46 participantes do estudo, ou seja, $70 \%$ do total, as imagens estereotipadas do Brasil e sua gente geram consequências diretas na convivência social nos países de acolhida, sendo este citado como o terceiro maior problema por estas lideranças comunitárias. Esta mesma percepção das lideranças também é mencionada neste artigo a partir de diferentes estudos e trabalhos de campo feitos com as comunidades brasileiras em alguns países. Porém, consideramos este levantamento recente importante, pois o trabalho destas lideranças junto ao governo brasileiro e outras instituições tem contribuído para o entendimento e busca de alternativas a fim de melhorar e ampliar estes imaginários, deixando de ser um dado meramente informativo e passando a ser uma informação para a transformação ${ }^{15}$.

${ }^{15}$ Desde 2008, o Ministério de Relações Exteriores do Brasil realiza as Conferências Brasileiros no Mundo. No total já foram realizadas quatro edições em que líderes da comunidade brasileira em diferentes países são convidados a debater e buscar soluções para os problemas enfrentados por suas comunidades. Neste âmbito, a temática de gênero é de grande relevância, sendo um 
Em outra pergunta do questionário os participantes responderam sobre as sugestões que tinham para resolver os temas. Em linha geral, várias respostas destacaram a importância de informar e capacitar as comunidades, além do fomento do diálogo com as comunidades de acolhida. Em algumas das sugestões dadas, os participantes mencionaram propostas diretas para melhorar a imagem do Brasil no exterior. Por exemplo, uma participante da Espanha sugere "utilizar a imprensa brasileira local e os sites de associações brasileiras, consulados, embaixadas e organizações internacionais para publicar guias sobre as questões de gênero". Já uma participante dos Estados Unidos propõe "melhoria da imagem da mulher brasileira pelos órgãos de turismo (já em andamento) e conscientização da comunidade". Em Portugal, a participante solicita "... publicidade de bons exemplos brasileiros. Exemplos que eduquem e que formem uma melhor imagem do Brasil que trabalha, que estuda, que se esforça e vence!".

\section{A hipervisualização das brasileiras na mídia espanhola}

Na Espanha, onde há uma presença significativa de imigrantes brasileiros, os diferentes trabalhos de pesquisa apontam para a construção de uma imagem estereotipada do Brasil. No caso da mulher brasileira, esses estudos evidenciam a predominância de uma imagem erotizada e sensual que, em muitos casos, associa a imigração de brasileiras com a questão da prostituição ${ }^{16}$.

Neste apartado buscamos apontar alguns dados de estudos realizados na Espanha que reforçam a importância e o protagonismo que as brasileiras adquirem na mídia e sociedade espanhola, principalmente os trabalhos de Badet $^{17}$. Silva ${ }^{18}$ argumenta que a visibilidade midiática do Brasil na Espanha está diretamente associada aos jogadores de futebol e ao samba carioca, dois temas amplamente difundidos nos meios de comunicação espanhóis. Já Cogo, Losa e Wulfhorst, ao entrevistarem brasileiros residentes em Barcelona, constataram que os imigrantes brasileiros não se sentem representados na mídia espanhola quando esta dá visibilidade a elementos como o samba, a praia, o carnaval e o futebol ${ }^{19}$.

tema sempre presente nas pautas a importância de trabalhar e combater os imaginários reduzidos sobre os brasileiros e brasileiras. Em 2015 aconteceu a "I Conferência de Gênero de Brasileiros pelo Mundo". Neste evento, a discussão sobre imaginários ganhou ainda mais relevância e foram propostas ações práticas para os problemas, muitas delas relacionadas à melhoria da imagem da comunidade brasileira no exterior.

${ }^{16}$ CAVALCANTI, Leonardo. O protagonismo empresarial imigrante a partir de uma perspectiva e gênero: o caso das brasileiras nas cidades de Madri e Barcelona; FALCONE, K. Os Imigrantes na Mídia Espanhola: Exclusão Social e Deslegitimação Discursiva; PISCITELLI, Adriana. Corporalidade em confronto: brasileiras na indústria do sexo na Espanha; BADET, op. cit.

17 Ibidem.

${ }^{18}$ SILVA, Denise T. Fotografias que revelam imagens da imigração: pertencimento e gênero como faces identitárias.

${ }^{19}$ COGO, Denise, GUTIÉRREZ, María, HUERTAS, Amparo (coords.). Migraciones transnacionales y medios de comunicación. 
Considerando estas análises prévias, desde 2008, Badet dedicou-se a analisar de maneira sistematizada a cobertura mediática sobre Brasil na Espanha ${ }^{20}$. Durante estes sete anos, foi coletado um amplo corpus de notícias de diferentes mídias sobre o Brasil na Espanha. Em um desses estudos, realizado em 2008, foram analisadas mais de 140 notícias sobre o Brasil, das quais 84 tiveram como tema central a imigração de brasileiros e brasileiras na Espanha ${ }^{21}$. O resultado da análise reafirmou o protagonismo midiático da mulher brasileira nos meios de comunicação espanhóis associado ao erotismo e à sensualidade.

Das 84 notícias analisadas sobre imigração brasileira, 15 foram relacionadas às trabalhadoras do sexo. Uma análise qualitativa deste corpus demonstrou que as notícias foram produzidas a partir de diferentes perspectivas, abrangendo notícias mais usuais sobre a desarticulação de uma máfia até notícias que abordam o problema do tráfico de pessoas. Porém, as imagens destas notícias são compostas por um padrão de cenas de detenção pela polícia, onde os corpos das brasileiras, assim como de outras vítimas, são destacados em primeiro plano e focados, muitas vezes, nas "bundas" das mulheres. É importante sublinhar também que todas estas notícias enfocavam o gênero feminino, ou seja, as mulheres brasileiras, contribuindo mais para estigmatizar do que compreender o assunto. A outra temática de destaque do corpus foram matérias sobre violência doméstica com 27 notícias ${ }^{22}$. No caso da análise qualitativa destes exemplos, observamos que a maioria das notícias analisadas destaca a nacionalidade da vítima e as possíveis relações amorosas entre o agressor e as vítimas brasileiras. Em resumo, este conjunto de notícias opta por ressaltar a figura feminina brasileira e associá-la a temáticas que podem ativar ideias ligadas ao imaginário sensual e erótico das mulheres brasileiras. Dito de outra maneira, a imagem que perpetua na mente de muitos estrangeiros de que a brasileira gosta de sexo, é uma mulher fácil e/ou está em busca de um relacionamento com um estrangeiro pode acabar por ser reforçada nos imaginários dos receptores dada a constante presença deste tipo de notícias nos meios de comunicação ${ }^{23}$.

${ }^{20}$ BADET, Maria. La construcción del imaginario social de la mujer brasileña y de Brasil en España: análisis de la recepción mediática junto a estudiantes de $4^{\circ}$ ESO de Barcelona, Sabadell y Sitges; IDEM. Televisión y construcción del imaginario de la mujer brasileña en España: propuesta de una metodología de análisis multidimensional; IDEM, Periodismo e imaginarios..., op. cit.

21 BADET, La construcción del imaginário..., op. cit.

22 Destacamos que o total de notícias sobre violência doméstica é numericamente maior que o de notícias sobre prostituição. Porém, o tempo total das notícias de violência doméstica acaba sendo menor, ou seja, são em geral notícias bem mais curtas (BADET, Televisión y construcción...., op. cit.).

${ }^{23}$ Diferentes guias e manuais sinalizam sobre a importância de uma cobertura midiática mais contextualizada e que contribua para compreender o grave problema da exploração sexual, como Guia para Jornalistas em Referência e Informações sobre o Enfretamento ao Tráfico de Pessoas. Do mesmo modo, manuais jornalísticos e estudos alertam para que não se tratem os casos de vítima de violência doméstica como "um caso mais", e sim como um problema social (DíEZ, Pilar López. Representación de género en los informativos de radio y televisión - Segundo Informe Representación de Género en los Informativos de Radio y Televisión). 
Outro dado que reforça o papel dos mass media espanhóis para a manutenção de imaginários sensuais e eróticos das brasileiras são algumas das 56 notícias de uma outra mostra estudada ${ }^{24}$. Neste conjunto encontramos diferentes notícias referentes a várias temáticas que facilmente acabam sendo associadas ao imaginário estigmatizado da mulher brasileira ${ }^{25}$ como, por exemplo, as revistas que usam a palavra "brasileiras", acompanhada de corpos nus ou com pouca roupa, como é o caso da Revista Vice (2007) na matéria "Chicas brasileñas" e da Revista El País Semanal (2009) na matéria "Cuerpos a la Brasileña". Outro exemplo são as matérias que tratam de temáticas que não estão relacionadas com o Brasil e, simplesmente, usam a imagem das brasileiras para chamar a atenção para a notícia, como é o caso da notícia da emissora Tele 5 sobre a proibição de uma corrida de bois em um vilarejo, onde mencionam que nem os encantos dos quadris das brasileiras foram capazes de alegrar a cidade.

Revista Vice - Vol. 3- 2007

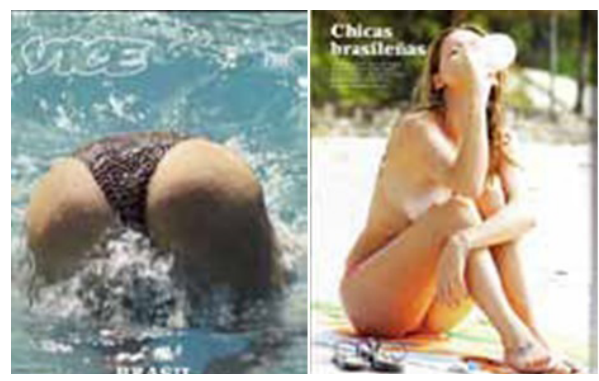

Revista El País Semanal -20/11/09

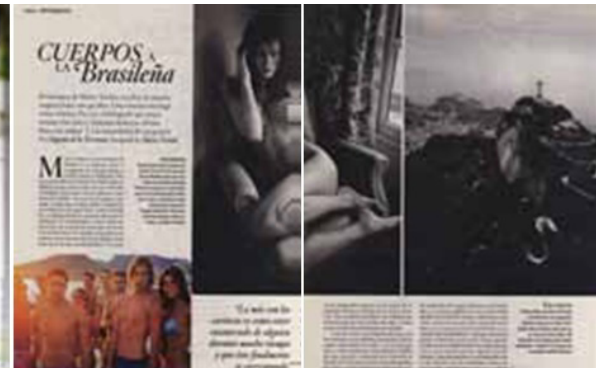

Exemplo matéria: Tele $5-02 / 08 / 08$

Início notícia: reportero (off canción brasileña de samba): ni las garotas brasileñas moviendo las caderas animan a los vecinos de Muños que este año se han quedado sin bueyes [...].

Ainda relacionado à presença de mulheres brasileiras na mídia espanhola, vale destacar a presença de notícias sobre a modelo Giselle Bundchen como símbolo e representante da mulher brasileira em diversos meios de comunicação espanhóis entre os anos de 2008 e 2010. Muitas destas notícias destacaram a nacionalidade da modelo e ela como a mulher brasileira mais internacional, acompanhadas de fotos e vídeos que destacavam a sua beleza física. Ainda que a presença da modelo possa, por um lado, representar uma ampliação do imaginário da mulher brasileira, deixando de associa-la às "mulatas" de corpos exuberantes, a presença da modelo, assim como outras modelos internacionais

\footnotetext{
${ }^{24}$ BADET, Periodismo e imaginarios..., op. cit.

${ }^{25}$ Embora nos estudos aqui mencionados também tenham sido encontrados exemplos de veiculação de outras imagens do Brasil, como aquelas relacionadas a questões políticas, econômicas, sociais e culturais, ainda é predominante a presença da imagem tropicalista do país na grande mídia da Espanha.
} 
brasileiras, podem também potencializar e reforçar em muitos imaginários a ideia de que as brasileiras são as mulheres de corpos sensuais e bonitos.

Porém, as associações mais diretas das brasileiras com a sensualidade e corpos perfeitos são observadas no período do carnaval, onde aparecem imagens do desfile das escolas de samba do Rio de Janeiro, que é tido como o carnaval mais importante do mundo. Os meios de comunicação tendem a mostrar imagens dos desfiles, associadas a discursos que destacam a alegria e a sensualidade do carnaval brasileiro. Em geral, encontram-se poucos exemplos de notícias que mostram outras facetas do carnaval no Brasil.

Das notícias sobre o carnaval analisadas, destaca-se um caso ocorrido em 2010 devido à associação do erotismo da mulher brasileira nos meios de comunicação com a imagem de uma criança considerada como "a mais nova rainha do carnaval brasileiro". Eram notícias sobre uma menina de sete anos aspirante ao título de Rainha do carnaval do Rio de Janeiro. Dada a idade da jovem, alguns setores criticaram sua participação afirmando que reforçava a utilização de crianças como objetos sexuais no país. Seguramente é um tema interessante e pertinente para o debate. Porém, o que se observou foi a utilização deste fato para estigmatizar ainda mais a mulher brasileira, inclusive as crianças. Muitas notícias associaram o fato de dançar no carnaval diretamente com o erotismo e a sensualidade. Um exemplo significativo desta utilização equivocada do fato é a noticia da emissora La Sexta, no dia 15 de fevereiro de 2010, que coloca na mesma discussão crianças pulando carnaval nas ruas e imagens da criança tida como a "nova rainha do carnaval". O texto chega a dizer que as crianças dançando nas ruas com seus pais são possíveis rivais e competidoras "da candidata à nova rainha".

La Sexta - 15/02/2010 - Reportero: [...] Como se no fuera suficiente hoy las calles de Rio se han llenado con más competidoras está no llega a los cuatro años y ya despunta en eso de bailar samba. Hasta los bebes se zarandean cuando escucha la batucada. [...].

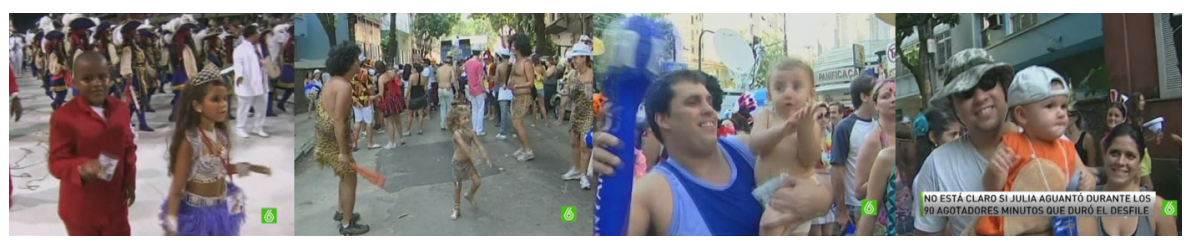

\section{A apropriação dos conteúdos midiáticos sobre Brasil na Espanha}

Para ilustrar como na prática acontecem os processos de apropriação de conteúdos midiáticos sobre o Brasil e como os mesmos podem ativar imaginários existentes e possibilitar a (re)criação de muitos outros, apresentamos alguns resultados do trabalho de campo realizado junto a 121 jovens de 14 a 16 anos de escolas catalãs. No trabalho, os jovens foram convidados a ler, ver e refletir sobre conteúdos midiáticos da mídia espanhola sobre o Brasil. Por meio de diferentes 
técnicas ${ }^{26}$ como: questionários abertos e fechados, debates em aula, grupos de discussão sobre as diferentes notícias e materiais extraídos da mídia sobre o Brasil, o trabalho demonstra na prática o que na atualidade vigora na mente de muitos jovens espanhóis sobre o país.

Vale relembrar que para analisar a imagem do Brasil existente hoje na Espanha, assim como em toda Europa, é preciso ter em conta uma série de fatores que vão, desde os primeiros contatos do continente com a cultura brasileira há 515 anos, que direcionou muito do imaginário para uma visão tropicalista que ainda vigora para muitos, até as representações do Brasil potencializadas pelo aumento dos fluxos recentes de imigração brasileira e, sem dúvida, o relevante papel do rápido e crescente avanço tecnológico que tem possibilitado, hoje, ao mundo estar conectado em rede e qualquer cidadão buscar e ampliar, por meio de diferentes mídias, suas visões e percepções das diferentes culturas, entre elas a brasileira.

A juventude é um campo pouco estudado e conhecido nas pesquisas relacionados aos mass media e âmbito educativo. No contexto espanhol, os estudos estiveram mais centrados na infância e poucos na juventude e sua interação midiática ${ }^{27}$. Por esse motivo é um campo interessante para análise. Além disso, consideramos que a escola é um espaço favorável às interações continuadas, já que permite aos jovens superar os estereótipos, aprender sobre a convivência e dinamização cultural. Por estes fatores foi que escolhemos a escola e os jovens como atores sociais relevantes para analisar a construção do imaginário do Brasil na Espanha ${ }^{28}$.

Neste apartado somente apresentaremos alguns dos resultados do trabalho de Badet ${ }^{29}$ que contribuem para a reflexão sobre o papel midiático na construção dos imaginários sobre o Brasil no exterior. Defendemos, assim como MartinBarbero $^{30}$, que vivemos um momento de repensar as relações na comunicação. Não podemos pensar o amplo mundo dos meios de comunicação à margem de uma nova perspectiva da comunicação. Passamos por uma mudança de perspectiva: antes, era pensada da emissão da mensagem até o momento da recepção, enquanto o paradigma atual considera as redes e as interfaces de proximidade, ou seja, qualquer receptor pode ser emissor.

${ }^{26}$ O trabalho é marcado pelo uso de diversas metodologias (MARTIN-BARBERO, Jesús. De los medios a las mediaciones: comunicación, cultura y hegemonía). O uso de multimetodologias é relevante para entender o processo complexo comunicativo. Porém, como argumenta Ibáñez (IBÁÑ̃EZ, Jesús. Más allá de la sociología. El grupo de discusión: técnica y crítica) as técnicas de pesquisa social estão destinadas a determinadas funções e o uso de mais de uma técnica é relevante para suprir as possíveis limitações de outra técnica.

${ }^{27}$ LUZÓN, Virginia. La imagen de los y las adolescentes en el prime time televisivo. Transmisión, consumo y recepción.

${ }^{28}$ BADET, Periodismo e imaginarios..., op. cit.

${ }^{29}$ Ibidem.

${ }^{30}$ MARTIN-BARBERO, Jesús. Claves de la investigación en las políticas de la comunicación y la cultura. 
No total participaram do estudo 121 alunos e alunas de cinco turmas de três escolas diferentes na Catalunha, uma no centro da cidade de Barcelona, duas turmas de uma escola na periferia da cidade industrial de Sabadell e uma turma da cidade de praia e turística de Sitges. A escolha das escolas seguiu critérios metodológicos detalhados nos trabalhos de Badet $^{31}$, buscando perfis diferentes de escolas e participantes. Entre os fatores observados na seleção estavam: o entorno social dos centros, presença de coletivos imigrantes na região do entorno escolar, perfis culturais, socioeconômicos e familiares. Portanto, trata-se de uma mostra diversa, o que permitiu observar diferentes percepções e leituras sobre as notícias apresentadas.

Depois de realizado um detalhado e amplo trabalho com os jovens sobre os conceitos de estigma e estereótipo, onde foram questionados sobre imagens que tinham de diferentes culturas e países, foi feito um jogo de palavras em que, individualmente, cada um devia responder que palavras lhes lembrava o Brasil, assim como outros países. No caso das respostas sobre o Brasil, os resultados demonstraram que, no imaginário destes adolescentes, três temáticas prevaleciam: uma cultural (samba, carnaval e dança), uma esportiva (futebol) e outra ambiental (praia). As menções ao carnaval e samba foram as mais significativas, manifestadas por 51 participantes $(42,1, \%)$, seguidas pela temática do futebol, mencionada por 18 adolescentes $(14,8 \%)$.

Para aprofundar no tema, em seguida foi feito um jogo de imagens em que os alunos tinham que dizer com qual país associavam cada imagem ${ }^{32}$. Das 15 imagens apresentadas, a mais reconhecida foi a imagem do carnaval do Brasil identificada por 94 participantes, chegando a ter quase $100 \%$ de acerto em algumas turmas. Ao mesmo tempo, uma das imagens com maior índice de erros foi outra representação do carnaval, só que dessa vez da Colômbia. De maneira equivocada, a maioria, 49 jovens, achou que era mais uma vez o carnaval do Brasil.

Essa tendência de associar o tema ao Brasil nos demonstra como esta festa popular está fortemente associada à imagem do Brasil nos imaginários da maioria dos jovens. Em um debate posterior, ao questionar o porquê das respostas, os jovens justificaram de diferentes maneiras: parte mencionando de maneira direta o papel dos meios de comunicação para associar Brasil ao Carnaval; outros a presença da manifestação cultural em seus países; alguns a imagem da mulher brasileira associada à beleza.

No mesmo jogo de imagens, também foram apresentadas duas fotos de mulheres, a primeira de uma modelo colombiana com biquíni e outra de uma

31 BADET, Periodismo e imaginários..., op. cit.

32 As imagens apresentadas eram referentes a países da América Latina, entre eles Brasil. Foram apresentadas imagens desde políticos, como Fidel Castro, milícias da Farc, pessoas com vestimentas típicas do Equador, jogadores de futebol da Argentina, índias brasileiras, modelo colombiana, carnaval no Brasil e na Colômbia. 
indígena brasileira. Na imagem da modelo colombiana, o Brasil voltou a ser a opção mais marcada por 54 participantes $(44,6 \%)$, sendo a opção correta, que era Colômbia, marcada por somente 10 jovens (8,3\%). Do mesmo modo, a imagem da índia brasileira foi marcada como sendo dominicana por uma maioria, 31 jovens, sendo que somente 5 marcaram de forma correta Brasil. Nos diferentes debates, as justificativas para as respostas demonstram uma vez mais a força que a imagem sensual e de corpos exuberantes das brasileiras tem nos imaginários de muitos, ainda que as declarações que justificam o porquê associaram a imagem a outros países demonstram que não é só a mulher brasileira que é relacionada ao corpo e à beleza. Por outro lado, nas respostas sobre a índia brasileira podemos observar o nível diferente de informação que alguns têm sobre o país, sendo os meios de comunicação utilizados mais uma vez para justificar as respostas.

Um dos temas que também surgiu nos debates em diferentes turmas nas escolas foi o caso da "mais nova rainha do carnaval" exposto anteriormente. Alguns participantes, principalmente da escola de Sitges $^{33}$, citaram o assunto como exemplo de notícia que haviam visto na mídia espanhola sobre o Brasil. Ou seja, no imaginário de muitos a imagem da pequena e dita como "sensual" menina brasileira dançando carnaval ficou guardada e, de alguma maneira, passou a influenciar na percepção destes jovens sobre o Brasil.

Já em outra etapa do trabalho de campo, durante os cinco grupos de discussão com seis alunos cada, totalizando trinta alunos, voltamos a observar e questionar as imagens e imaginários dos jovens sobre a mulher brasileira. Desta etapa, destacamos categorizações feitas, a partir de respostas livres e abertas, sobre as imagens que os faziam lembrar a mulher brasileira. A metade das respostas associou diretamente ao corpo e beleza, 20\% ao carnaval e 30\% foi capaz de apresentar outros imaginários da mulher brasileira. Mais uma vez, os meios de comunicação voltam a ser citados como fomentadores desta imagem do Brasil e da mulher brasileira associada à beleza, sensualidade e carnaval.

(41 - española): Una mujer guapa y con buen cuerpo, porque así es el prototipo de mujer que sale en la televisión.

(57 - ecuatoriana): Mujer con mucho cuerpo y bien formadas y morenas. Porque así las veo por televisión y por la calle.

(70 - español): Chicas guapas con cuerpos esculturales. Porque es lo que los medios me han incentivado, lo que a lo mejor les interesa resaltar.

Por outro lado, estão aqueles receptores que apresentaram apropriações diferenciadas sobre a imagem que tinham da mulher brasileira. Desde uma aluna brasileira que destaca o lado trabalhador das conterrâneas, até uma aluna recém${ }_{33}$ O trabalho de campo na escola de Sitges aconteceu em data próxima ao Carnaval em que foi destacado
o caso da mais "nova rainha do carnaval", sendo mencionado por cinco participantes durante a aula. 
chegada do Marrocos que nunca tinha ouvido falar do Brasil e, portanto, não tinha uma imagem pré-estabelecida.

(2 - brasileña): Una mujer trabajadora que cada vez más consigue avanzar y disminuir la diferencia entre hombres y mujeres.

(88 - marroquí): Tu eres la única, la primera brasileña que he visto y son guapas.

Outro material trabalhado nos grupos de discussão foram as matérias das televisões coletadas em 2008 sobre mulheres brasileiras associadas à prostituição. Neste âmbito, foi possível observar que os processos de percepção do tema variavam. Ou seja, por mais que os meios de comunicação e os imaginários coletivos do Brasil tendam a transmitir discursos com determinadas intenções, o processo de percepção e posterior apropriação dos conteúdos não é padrão e igual para todos os receptores das mensagens. Neste caso, o trabalho possibilitou ver cinco principais perfis de receptores: acreditam existir um protagonismo informativo das brasileiras; mencionam que o tema também é associado nas notícias a outros países; centram em destacar a maneira como as mídias informam o assunto; fazem associação da prostituição com a imagem da mulher brasileira; participantes que fizeram comentários diferenciados sobre o assunto.

Buscando fomentar e abrir espaço para outros imaginários do Brasil, trabalhamos com os alunos os conteúdos da revista Vice ${ }^{34}$. A proposta deste trabalho era deixar a livre escolha dois conteúdos que haviam chamado mais atenção e interesse dos participantes. Apesar da capa com a "bunda" de uma brasileira e uma matéria com fotos de brasileiras de biquíni fazendo topless, este não foi o assunto que mais despertou o interesse dos participantes, que ficou atrás da notícia "Uma parada no corredor da cocaína". Além disso, os resultados demonstraram uma diversidade de interesses temáticos, sendo 16 assuntos diferentes escolhidos como, por exemplo: tráfico, música, comunidade indígena, arquitetura brasileira, moda e beleza.

Os diferentes exemplos de apropriação midiática aqui expostos evidenciam o importante papel dado pelos jovens receptores à mídia como configuradora dos imaginários sociais do Brasil. Os resultados também reforçam o protagonismo das mulheres brasileiras no imaginário destes adolescentes para retratar a imagem que têm do Brasil, principalmente através do samba, carnaval e mulheres de corpos exuberantes. Ao mesmo tempo, podemos ver que, quando provocados, os jovens conseguem extrapolar ao midiatizado em grande escala sobre o Brasil e exercer um papel crítico sobre a influência da mídia para configurar os imaginários mais usuais sobre o país.

${ }^{34}$ A revista Vice é composta por uma variada gama de assuntos que vão desde notícias sobre o corredor da cocaína, mulheres brasileiras, matéria sobre massacre em uma prisão, uma viagem de um aventureiro pela Amazônia, os segredos do personagem Zé do Caixão, pílulas brasileiras, festival de música eletrônica brasileira, reportagem sobre índios e agricultores, crianças da bíblia e outras. 


\section{Novos horizontes para os imaginários do Brasil}

Os diferentes estudos e análises realizados demonstram, na prática, como são complexos e dinâmicos os processos de recepção e posterior apropriação dos conteúdos midiáticos. Como se observou, não são processos homogêneos, tampouco é fácil entender seus motivos e origens. Como todos os estudos ancorados no entendimento das interações sociais, os resultados, principalmente do trabalho de campo com jovens espanhóis, demonstram que existem possibilidades para ampliar a construção do imaginário social da mulher brasileira e do Brasil, sendo os meios de comunicação de suma importância para potencializar a ampliação e a diversificação de conteúdos e imagens do país.

Neste cenário, constatamos que nos últimos anos o tema da imagem internacional do Brasil e suas consequências tem ganhado cada vez mais atenção. Observa-se uma mudança de posicionamento por parte do governo brasileiro, o qual tem trabalhado para a promoção da diversidade social e cultural do Brasil. Como exemplo, podemos citar os anúncios publicitários da Embratur que, no passado, foi criticada por divulgar publicidades que contribuíam para erotizar a imagem da mulher brasileira e, já nos últimos anos, passou a apresentar campanhas que mostram a diversidade social, histórica e natural do Brasil, sem recorrer à estratégia de exposição excessiva dos corpos de mulheres brasileiras ${ }^{35}$. Além disso, associações de imigrantes brasileiros em diferentes países têm trabalhado para mostrar a cultura brasileira em suas diferentes facetas, não apenas focada no samba e no carnaval, mas também nas festas juninas, nos grupos de choro, na música popular brasileira, nas danças regionais típica, dentre outras. Sem dúvida, esses esforços têm contribuído para a produção de uma imagem mais ampla e diversificada do país e para a construção de imaginários nacionais para além da tropicalidade.

Como demonstrado neste texto, quando ofertadas diferentes opções de conteúdo e informações sobre o Brasil, as mesmas passam a ser apropriadas por muitos receptores. No estudo realizado junto aos 121 jovens na Espanha, constata-se que nos processos de apropriação dos conteúdos informativos vigorava o imaginário tropical e sensual da mulher brasileira. Porém, o trabalho realizado também demonstrou que a reflexão crítica e a oferta de conteúdos diversos também potencializam novas leituras e diferentes formas de ver o Brasil, a mulher e o homem brasileiros.

Do mesmo modo que Cogo e Brignol ${ }^{36}$ e Martin-Barbero ${ }^{37}$, acreditamos que é fundamental avançar ainda mais na realização de estudos empíricos sobre os processos de apropriação e empoderamento dos conteúdos midiáticos, sendo o âmbito dos estudos sobre os imaginários sociais do Brasil no exterior um campo

\footnotetext{
${ }^{35}$ BADET, Periodismo e imaginários..., op. cit.

${ }^{36}$ COGO, Denise, BRIGNOL, Liliane. Redes sociais e os estudos de recepção na internet.

${ }^{37}$ MARTIN-BARBERO, Claves de la investigación..., op. cit.
} 
rico para análise e reflexão. Os diferentes estudos e trabalhos mencionados neste artigo são um importante contributo para ampliar o debate e sensibilizar sobre a importância do tema em suas diversas facetas e dimensões, desde os imaginários mais fortemente presentes sobre o país para muitos estrangeiros, até as possibilidades e estratégias midiáticas possíveis para contribuir para a ampliação dos mesmos.

\section{Bibliografia}

BADET, Maria. Periodismo e imaginarios: Brasil más allá de lo tropical y lo sensual. Barcelona: Editorial UOC, 2015.

BADET, Maria. La construcción del imaginario social de la mujer brasileña y de Brasil en España: análisis de la recepción mediática junto a estudiantes de $4^{\circ}$ ESO de Barcelona, Sabadell y Sitges. Barcelona: UAB, 2011.

BADET, Maria. Televisión y construcción del imaginario de la mujer brasileña en España: propuesta de una metodología de análisis multidimensional. Barcelona: Tesina de maestría, Facultad de Ciencias de la Comunicación. Universitat Autónoma de Barcelona, 2009.

BARKER, Chris. Televisión, globalización e identidades culturales. Barcelona: Ediciones Paidós Ibérica, 2003.

BUXÓ, María Jesús; MIGUEL, Jesús de (eds.). De la investigación audiovisual. Fotografía, cine, video, televisión. Barcelona: Proyecto a ediciones, 1998.

CAVALCANTI, Leonardo. O protagonismo empresarial imigrante a partir de uma perspectiva e gênero: o caso das brasileiras nas cidades de Madri e Barcelona. Seminário Internacional - Fazendo Gênero 7, Santa Catarina, 2006.

COGO, Denise. Los Estudios de Recepción en América Latina: perspectivas teóricometodológicas. Portal de la Comunicación. Instituto de la Comunicación (InCOM) de la UAB (Universidade Autônoma de Barcelona), Barcelona, 2009.

COGO, Denise; BRIGNOL, Liliane. Redes sociais e os estudos de recepção na internet. Matrizes (USP. Impresso), v. 4, 2001, p. 75-92.

COGO, Denise; GUTIÉRREZ, María; HUERTAS, Amparo (coords.). Migraciones transnacionales y medios de comunicación. Relatos desde Barcelona y Porto Alegre. Madrid: Catarata, 2008.

DíEZ, Pilar López. Representación de género en los informativos de radio y televisión. Segundo Informe Representación de Género en los Informativos de Radio y Televisión - Instituto de la Mujer - Ministerio de Trabajo y Asuntos Sociales. Madrid: Instituto Oficial de Radio y Televisión, RTVE, 2005.

FALCONE, K. Os Imigrantes na Mídia Espanhola: Exclusão Social e Deslegitimação Discursiva. XI Seminário Apec: Inmigración y Territorio. Barcelona: Apec, 2006, p. 189-198.

FERIN CUNHA, Isabel (coord.). A televisão das mulheres: ensaios sobre recepção. Lisboa: Quimera/Bond, 2006. 
GARCÍA, Loreley. La migración de brasileños en el contexto de la globalización. Migraciones Internacionales, v. 3, n. 1. 2005, p. 165-173.

IBÁÑEZ, Jesús. Más allá de la sociología. El grupo de discusión: técnica y crítica. Madrid: Siglo Veintiuno editores, 1979.

LUZÓN, Virginia. La imagen de los y las adolescentes en el prime time televisivo. Transmisión, consumo y recepción. Madrid: Ministerio de Trabajo y Asuntos Sociales - Instituto de la Mujer, 2009.

MACHADO, Igor J. Imigrantes brasileiros no Porto. Aproximação à perenidade de ordens raciais e coloniais portuguesas. Lusotopie, v. 11, 2004, p. 121-140.

MARTIN-BARBERO, Jesús. De los medios a las mediaciones: comunicación, cultura y hegemonía. México: Gustavo Gilli, 1987.

MARTIN-BARBERO, Jesús. Claves de la investigación en las políticas de la comunicación y la cultura. Barcelona: Fundación CIDOB/Cátedra UNESCO de Comunicación. InCom-UAB), 2008. Série Dinâmicas interculturales, n. 11, 2008.

MINISTÉRIO DA JUSTIÇA. Relatório Nacional sobre Tráfico de pessoas: consolidação dos dados de 2005 a 2011. Brasília: Ministério da Justiça, 2013.

MINISTÉRIO DAS RELAÇÕES EXTERIORES DO BRASIL. Estimativas de brasileiros no exterior, 2013.

MULVEY, Laura. Placer visual y cine narrativo. Eutopías, 2a época, v. 1. Valencia: Ediciones Episteme, 1989.

$\mathrm{NASH}$, Mary. Repensar las representaciones mediáticas de las mujeres inmigrantes. Institut Europeu de la Mediterrànea. Quaderns de la Mediterrània, n. 7. Barcelona: Universidad de Barcelona, 2007, p. 56-62.

$\mathrm{NASH}$, Mary. Representaciones culturales, imaginarios y comunidad imaginada en la interpretación del universo intercultural. AA.VV. La política de lo diverso. ¿Producción, reconocimiento o apropiación de lo intercultural? I Training Seminar de jóvenes investigadores en Dinámicas interculturales. Barcelona: Fundación Cidob., 2008, p. 13-22.

OIT. Enfrentamento ao tráfico de pessoas no Brasil (2004-2011): avaliações e sugestões de aprimoramento de legislação e políticas públicas. Brasília: 2012.

PADILLA, Beatriz. Brasileras en Portugal: de la transformación de las diversas identidades a la exotización. Amérique Latine Histoire \& Mémoire. Feemes latinoaméricaines et migrations, n. 14, 2009, p. 1-14.

PISCITELLI, Adriana. Corporalidade em confronto: brasileiras na indústria do sexo na Espanha. Revista Brasileira de Ciências Sociais, v. 22, n. 64. 2007, p. 17-32.

PISCITELLI, Adriana. Trânsitos: brasileiras nos mercados transnacionais do sexo. Rio de Janeiro: EUDUERJ, 2013.

PONTES, Luciana. Mulheres brasileiras na mídia portuguesa. Caderno Pagu, n. 23, 2004, p. 229-256. Disponível em: <http://www.scielo.br/pdf/cpa/n23/n23a08. pdf $>$. Acesso em: junho, 2008.

RIBEIRO, Gustavo Lins. Identidade Brasileira no Espelho Interétnico. Essencialismos e Hibridismos em San Francisco. Série Antropologia, Brasília, v. 241, 1998. 
RIBEIRO, Gustavo Lins. Tropicalismo e Europeísmo. Modos de representar o Brasil e a Argentina. In FRIGERIO, Alejandro; RIBEIRO, Gustavo Lins (orgs.). Argentinos e Brasileiros. Encontros, Imagens e Estereótipos. Petrópolis: Vozes, 2002.

SALES, Teresa; LOUREIRO, Márcia. Imigrantes brasileiros adolescentes e de segunda geração em Massachusetts, EUA. Revista Brasileira de Estudos de População, v. 21, n. 2. Campinas, 2004.

SILVA, Denise T. Fotografias que revelam imagens da imigração: pertencimento e gênero como faces identitárias. Tese de doutorado. PPG Ciências da Comunicação. Universidade do Vale do Rio dos Sinos, 2009.

SILVA, Marcos. Dinâmicas da Migração Brasileira e Crise do Welfare State na UE Pós-2008: Uma Etnografia a partir de Roma e Barcelona. Tese de Doutorado em Antropologia. UFPE, 2013.

UNODC. Global Report on Trafficking in Person 2012. Nova York, 2012.

\section{Abstract}

Prevalence of stereotypical imaginary of Brazil abroad and the role of media in its maintenance

This article shows the importance of the communication channels as a contributor to the development of a Brazilian image abroad. The paper presents the results of Badet's (2015) studies comprised of analyses of more than 160 news about Brazil in the Spanish media. The study also analyses how the media contents can be interpreted. The results are based on field works of two years conducted with 121 Spanish young adults. The results show the mediatic and social importance of Brazilian women as a contribute to the social image of Brazil developed abroad. This image is often associated to eroticism and sensuality. The results of these studies suggest the important role of media in the construction of Brazilian image with less stereotypes.

Keywords: social image of Brazil, media content.

Recebido para publicação em 29.02.2016

Aceito para publicação em 28.03.2016 Received for publication in February 29 ${ }^{\text {th }}, 2016$

Accepted for publication in March 28 ${ }^{\text {th }}, 2016$

ISSN impresso 1980-8585

ISSN eletrônico 2237-9843

http://dx.doi.org/10.1590/1980-85852503880004605 